\title{
The evolution of social innovation and its global research trends: A bibliometric analysis
}

\author{
Huma Sikandar*, Umar Haiyat Abdul Kohar², Sidra Salam³ \\ ${ }^{1,2,3}$ Azman Hashim International Business School (AHIBS), Universiti Teknologi Malaysia (UTM), 81310, Johor Bahru, \\ Johor, Malaysia
}

*Corresponding Author email: huma.sikandar@gmail.com

Submission: 04 October 2020

Revised: 25 December 2020

Accepted: 02 February 2021

\begin{abstract}
The field of social innovation (SI) has received a growing interest from academia and policymakers from the past two decades. This research aims to identify research trends in the field of social innovation. For this purpose, we have carried out a bibliometric analysis on data from the previous 54 years, i.e. 1966-2019 from the Scopus database. This analysis is based on a bibliometric analysis of all published 'articles' in the SCOPUS database. The phrase "Social Innovation" was searched in title or abstract to search for the relevant articles. This research is carried out to investigate parameters such as publications in line with the years, subject areas, top journals, top authors and countries contributing to the SI field, collaborations and co-occurrence of keywords. Finding demonstrated that Frances R. Westley (University of waterloo) is the most prolific author in the SI field. Additionally, through an analysis of the top journals, we identified that 'Sustainability' is the top journal and that field is multidisciplinary. We have noticed a significant increase in the published articles in social innovation domain since 2016. This leads us to the conclusion that the topic has gained relevance among the academicians in recent years. The number of publications are expected to increase following this publication trend. We used VoS Viewer visual bibliometric analyser to identify the cooccurrence of keywords and co-authorship of countries. We found that Innovation, Social Entrepreneurship, Social Enterprises, Sustainability, Corporate Social Responsibility (CSR) and governance are the focus areas of social innovation research. Some variables with infrequent occurrences, limitations and future recommendations are also discussed.
\end{abstract}

Keywords: Social Innovation, Systematic Review, Bibliometric Analysis, VoS Viewer

\section{INTRODUCTION}

The concept of social innovation (SI) differs from its other counterpart innovations in a way that it focuses on social needs or a solution to a social Problem (Wijk et al., 2019). Social Innovation is defined as "innovative activities and services that are motivated by the goal of meeting a social need and that are predominantly diffused through organisations whose primary purposes are social" (Mulgan, 2006). One of the reasons behind the growing interest of academician and practitioners in Social Innovation business and management field is the significant dissatisfaction of organisations and entrepreneurs towards the solution to social problems (Caroli et al., 2018; Mirvis et al., 2016). Social innovation is considered a concept that acts as a management strategy to strengthen the relation of enterprise-society and aims to improve environmental conditions (Blanco-Ariza et al., 2019).

The concept had gained its relevance since the last two decades when the traditional solutions appeared to seem inadequate to address the deep-rooted social problems 
(Ozbag et al., 2019). Social Innovation is a mechanism that generates new ideas to produce sustainable solutions for social problems. Social Innovation is a process that consists of idea generation, implementation and growth (Murray et al., 2012). That's why over the past decade academicians and policymakers have shown a significant interest in Social Innovation. Despite its growing popularity, the concept of social innovations is still scattered and fragmented (Caroli et al., 2018; Foroudi et al., 2020; Mulgan, 2006; Ozbag et al., 2019; Weerakoon et al., 2016). Therefore the field lacks conceptual clarity and theoretical foundations which raises an essential question as what are the characteristics of social innovation?

The objective of this study is, therefore, to examine the research patterns and latest trends of social innovation scientific publications. There have been several reviews and bibliometric studies conducted in the field of SI (Agostini, M. R., Vieira, L. M., Tondolo, R. P., Vilmar Antonio Gonçalves Tondolo, 2017; Blanco-Ariza et al., 2019; Gaitán-Angulo et al., 2018; Ozbag et al., 2019; Pacheco et al., 2018; Silveira \& Zilber, 2017; van der Have \& Rubalcaba, 2016; Weerakoon et al., 2016; Westley et al., 2018). This study, to the best of our knowledge, incorporates all the research publications from 1966 to 2019 based on the Scopus database. The previous reviews are conducted either on different databases or are based on older Scopus data.

\section{METHODOLOGY}

This study is conducted using the Scopus database. This database has been selected as a research platform for several reasons. First, the Scopus database is one of the largest abstract and citation-based databases of peer-reviewed literature with comprehensive global and regional coverage of journals, books and conference proceedings (Baas et al., 2020). Second, most of the articles published on other databases have their abstracts indexed in Scopus, so it gives extensive coverage of articles. Thus, from this database, the sample could be expanded to other databases using the snowball sampling method (Silveira \& Zilber, 2017).

Additionally, Scopus is user-friendly and supports many software tools that enable the retrieval of necessary data for the bibliometric analysis such as authors, title, publishing year, cited references, abstracts, institutions and countries. It also enables a preliminary analysis concerning the number of citations over the years and the identification of the most cited authors and articles.

\subsection{ANALYSIS}

Through bibliometric analysis, the researchers statistically examine the authors, institutions, country, and cooperation's among authors, subject areas, and keywords and published articles in the given period in the Social Innovation field. In this regard, this study addresses the following research questions

1. How has the concept of Social Innovation evolved over the years?

2. What are the most productive journals, countries and institutions related to SI literature? 
3. Who are the most prolific authors in the given area?

4. Which authors have contributed the most by doing collaborative research?

5. Which countries have contributed the most by doing collaborative research?

\subsection{Search Strategy and Sample Collection}

The data for this study was gathered in the second week of December 2020 using the SCOPUS database and focused on 54 years from 1966-2019. The leading search keyword was "Social Innovation". We applied the quotation marks to obtain an interconnection between the word 'innovation' and the word 'social', thus excluding works on innovation in general. The search included the term 'Social Innovation' in title and abstract. We initially identified 3140 search results in SCOPUS database based on the research criteria. We decided to choose the term' social innovation' only, just to limit the search to articles on this theme. The search string used is TITLE-ABS ("Social Innovation"). We purposely did not search for any related terms to avoid confusions in similar terminologies and to keep the study simple to achieve the desired objectives.

The next step of the search is to include just research articles published until 2019 thereby ignoring the rest of the studies (for example, book chapters and conference papers etc.) and excluding papers published in the year 2020 and 2021. We used the following string in order to get our desired research articles: TITLE-ABS ("social innovation") AND (LIMIT-TO (SRCTYPE, "j")) AND (LIMIT-TO (DOCTYPE, "ar")) AND (EXCLUDE (PUBYEAR, 2020) OR EXCLUDE (PUBYEAR, 2021)). The search results we identified were 1443 in this step. In the next step, we intended to check for the existence of identical works. We removed any review or meta-analysis articles present in the set of results that we identified. The results we got from the search were 300 articles. We then identified the review articles manually from this list in order to ensure that no review article or meta-analysis articles in our analysis. As a result of this round of search strategy, we identified 162 review articles that were missed in the previous stage because their title and abstract didn't use the right words in the title and abstract to identify the article type. The EID of these articles were noted down, and in the next step, they were removed from the search string. As a result, we identified 1280 research papers as a part of this bibliometric study (see Fig. 1). The step by step process of data collection and search strategies is provided in table 4 (appendix). 


\section{Main Query Searched}

3140 records identified by "Social Innovation" in Title and Abstract

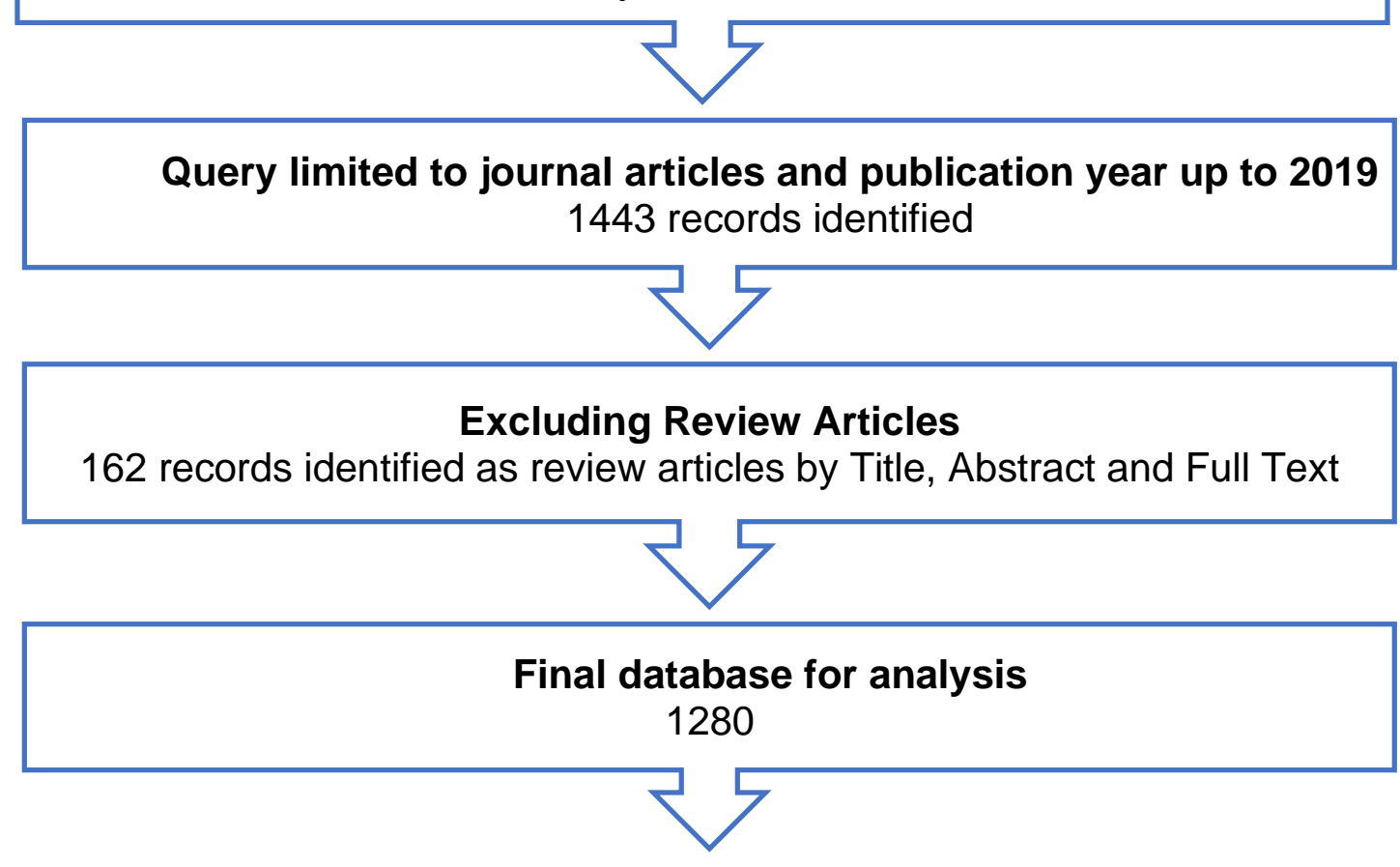

Fig. 1. Search and Selection of articles

\subsection{BIBLIOMETRIC MAPS}

This study aims to map and analyse scientific production concerning social innovation through a bibliometric study. Using bibliometric methods, we attempted to obtain an overview of the intellectual structure of the fields of SI, identifying author countries and author keywords patterns.

We exported the data of author publication details obtained from the Scopus database into VoS viewer to create and visualise bibliometric maps. VoS viewer is a software tool used for creating and visualising bibliometric maps. This study focuses on the author keywords and author affiliated countries, so bibliometric maps for both were created to analyse its data. All the items (nodes) in a map will be connected through association-link (a broad or a thin line), which will show its strong or weak association. For instance, a higher number (represented in digits) suggests a strong relationship with another node.

In co-authorship analysis, the link strength among different countries represents the number of articles that are co-authored by authors affiliated with different countries. On the other hand, total link strength demonstrates the total strength of co-authorship links of a specific country with different countries. Similarly, in co-occurrence analysis, links among authors keywords represent the research articles where two keywords appear together (van Eck \& Waltman, 2014). While doing co-authorship analysis, our finding suggested that the work of 1280 authors selected as a part of this study were associated with 84 countries. These 84 countries were then categorised into 5 clusters according to their continents, i.e. Europe, America, Asia, Africa and Oceania. 
In co-occurrence of keywords analysis, we identified 97 keywords used in 1280 research articles understudy. The total number of keywords were found to be 118, but after deletion of irrelevant keywords and gathering similar keywords, we created a map using 97 keywords used in social innovation research. We re-labelled similar keywords and merged them into one group such as social innovation and social innovations were merged into on keyword, i.e., social innovation. Similarly, grassroots innovation and grassroots innovations were labelled as grassroots innovation, inclusion and social inclusion in social inclusion etcetera. Using this technique, we managed to remove ten repeated/identical keywords. The remaining 97 keywords were used to create the map to examine the research trend among the keywords co-occurrences.

\section{RESULTS AND ANALYSIS}

\subsection{EVOLUTION OF PUBLICATIONS OVER YEARS}

According to our search results, 3140 papers were found to be published over 54 years from 1966-2019. The first-ever article related to Social Innovation was published in 1966. Subsequently, the number of publications in the said area remained under ten publications per year until the year 2004 with more than 80 publications. After 2010 an exponential growth is recorded in the number of publications per year. It was only after 2005 that Social Innovation construct gained popularity in academic literature and became more familiar to researchers. The growth of social innovation has been highlighted by many researchers, including (Fraisse, 2013; Jessop et al., 2013; Moulaert et al., 2013; Pacheco et al., 2018). The evolution of Social Innovation research articles from 1966 to 2019 is shown in Fig. 2. Fig. 2 shows that year 2019 is the year with most publications in the area under study. It is important to note that $50 \%$ of the articles on Social Innovation were published during the last four years, 2016-2019. It is anticipated that the annual publications will continue to increase in the following years.

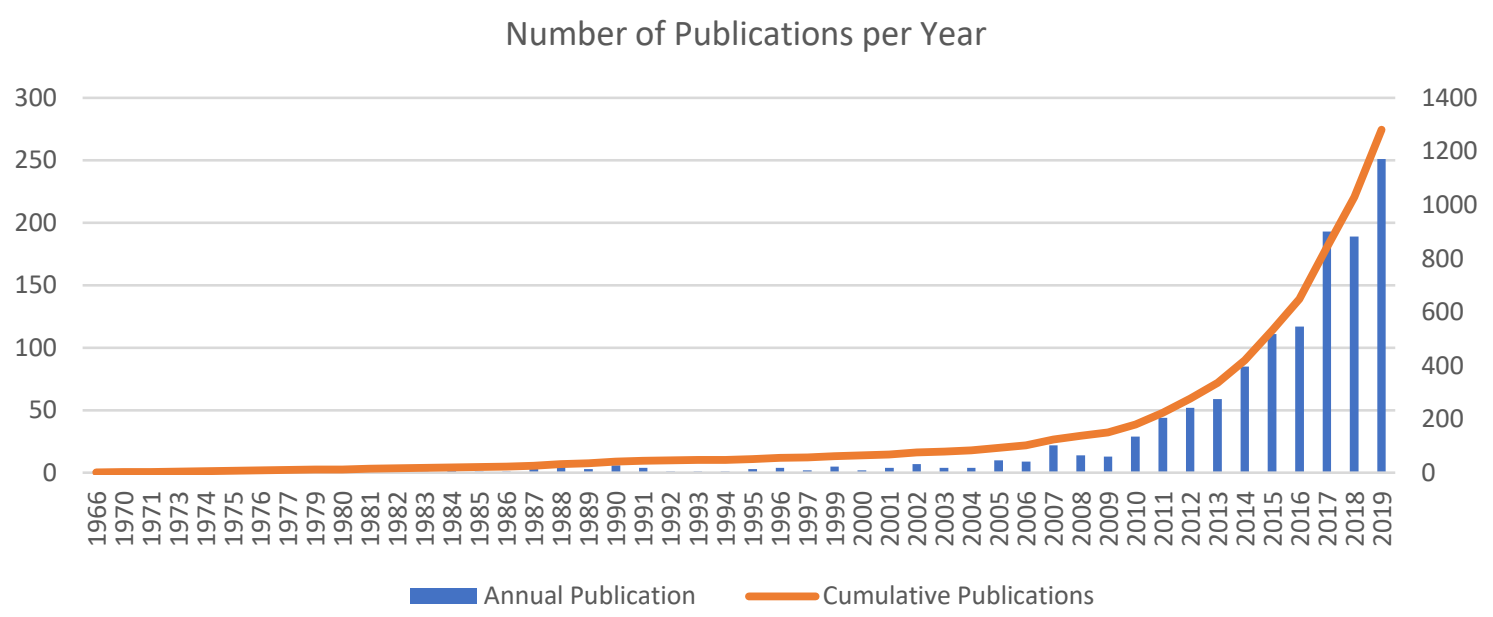

Fig. 2. Publications on Social Innovation (1966-2019)

The concept of social innovation that we know of today gained its relevance from the work of (Taylor, 1970) and (Gabor, 1970). It was only after 2005 that the concept of social innovation 
expanded its profile, thereby, recording a significant boost to the number of publications on the concept. Various authors (Fraisse, 2013; Jessop et al., 2013; Moulaert et al., 2013; Pacheco et al., 2018) also confirm this evolution in research as from this point in time.

\subsection{Distribution by SUBJect AREA}

Social Innovation has emerged as a fairly heterogeneous construct and is studied in different fields of knowledge (Pacheco et al., 2018), so we sought to identify these different fields in which social innovation is being studied and has made its contribution in the last 54 years. Fig. 3 shows the distribution of Social Innovation articles in different fields of knowledge. It is evident from the figure that 33\% (being the highest) of the total publications are published in the Social Sciences area while $17 \%$ of the total publications in the area of Social Innovation are published in the business and management field and accounting filed. Similarly, there are $9 \%$ of publications in Environmental Science and $8 \%$ in Economics and Finance subjects. Other 10\% of the publications belong to 15 different fields with less than 70 publication in their respective areas.

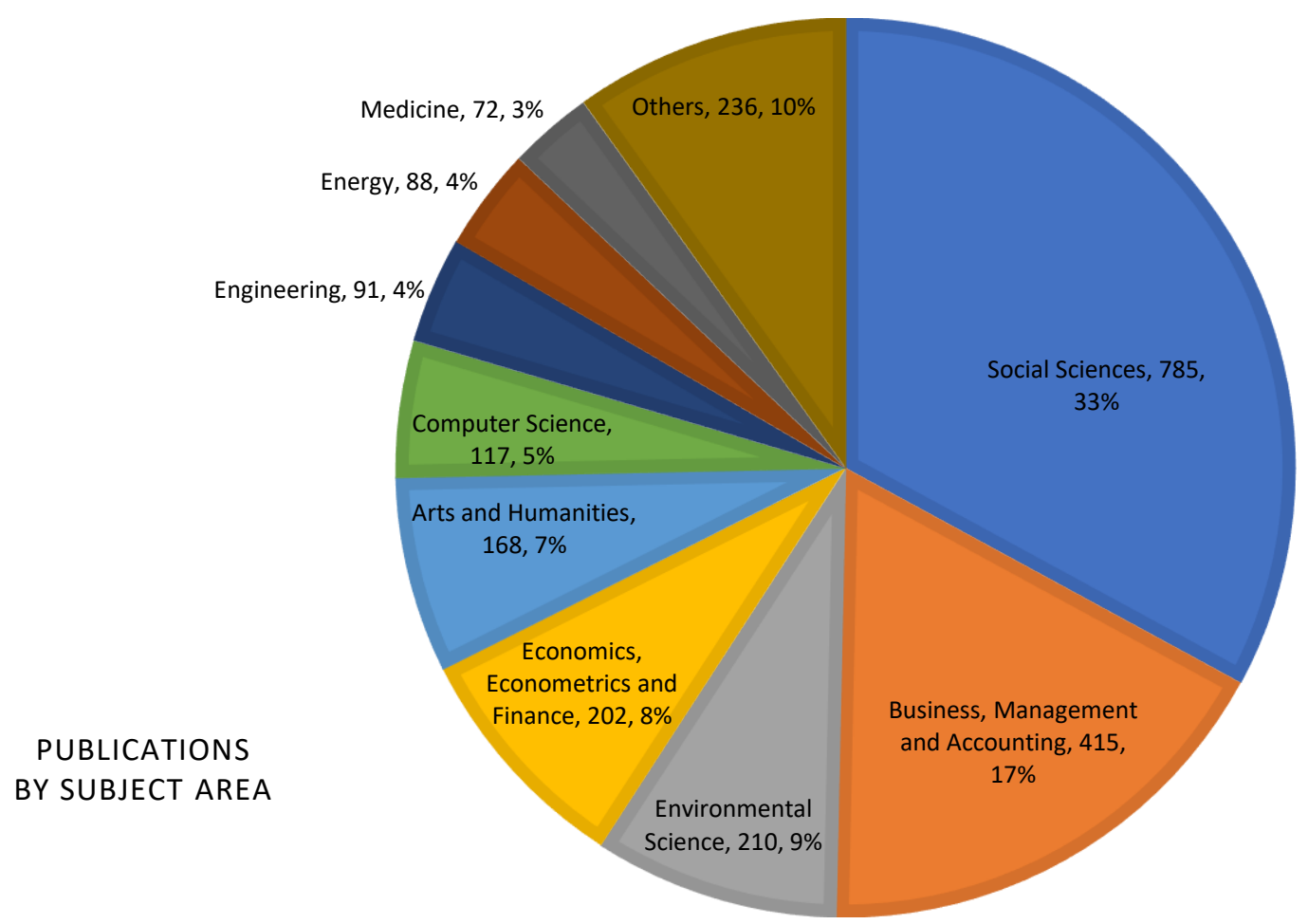

Fig. 3. Distribution in fields of knowledge

\subsection{ANALYSIS OF JOURNALS}

We carried out an analysis of the top five journals that have published articles on Social Innovation and found that the Sustainability journal has the highest number of publications in the Social Innovation field with $3.28 \%$ of the total publications. In contrast, the Design Journal is ranked second, with $2.42 \%$ of the total publications. Similarly, the contribution of the Journal of Social Entrepreneurship is $1.79 \%$ while Ecology and Society and Innovation journal have published $1.25 \%$ and $1.01 \%$ of the total articles respectively. Table 1 summaries the details of the top five journals. Our analysis shows that top 5 journals 
are owned by 3 different publishers (table 1). Multidisciplinary Digital Publishing Institute (MDPI) is the publisher of the most productive journal while Taylor \& Francis owned three of the top 5 journals such as Design journal, Journal of Social Entrepreneurship, and innovation. Another top publisher is The Resilience Alliance.

Table 1. Top 5 journals on Social Innovation

\begin{tabular}{|c|c|c|c|c|c|c|c|}
\hline Rank & Journal & $\begin{array}{l}\text { Total } \\
\text { Publicati } \\
\text { ons (\%) }\end{array}$ & $\begin{array}{l}\text { Number } \\
\text { of } \\
\text { Citations }\end{array}$ & $\begin{array}{l}\text { Cite } \\
\text { Score } \\
2019\end{array}$ & The most cited article & $\begin{array}{l}\text { Times } \\
\text { cited }\end{array}$ & Publisher \\
\hline 1 & $\begin{array}{l}\text { Sustainability } \\
\text { Switzerland }\end{array}$ & $\begin{array}{l}(42) \\
3.28 \%\end{array}$ & 225 & 3.2 & $\begin{array}{l}\text { Enabling value co-creation } \\
\text { in the sharing economy: } \\
\text { The case of mobike }\end{array}$ & 38 & $\begin{array}{l}\text { Multidisciplinary } \\
\text { Digital Publishing } \\
\text { Institute (MDPI) }\end{array}$ \\
\hline 2 & Design Journal & $\begin{array}{l}(31) \\
2.42 \%\end{array}$ & 41 & 0.6 & $\begin{array}{l}\text { Inclusive design, audio } \\
\text { description and diversity of } \\
\text { theatre experiences }\end{array}$ & 10 & Taylor \& Francis \\
\hline 3 & $\begin{array}{l}\text { Journal of Social } \\
\text { Entrepreneurship }\end{array}$ & (23) $1.79 \%$ & 251 & 2.6 & $\begin{array}{l}\text { Scaling Social Impact: } \\
\text { Building Sustainable Social } \\
\text { Ventures at the Base-of- } \\
\text { the-Pyramid }\end{array}$ & 37 & Taylor \& Francis \\
\hline 4 & $\begin{array}{l}\text { Ecology and } \\
\text { Society }\end{array}$ & (16) $1.25 \%$ & 634 & 7.5 & $\begin{array}{l}\text { Surmountable chasms: } \\
\text { Networks and social } \\
\text { innovation for resilient } \\
\text { systems }\end{array}$ & 182 & $\begin{array}{l}\text { The Resilience } \\
\text { Alliance }\end{array}$ \\
\hline 5 & Innovation & (13) $1.01 \%$ & 114 & 2.9 & $\begin{array}{l}\text { Social innovation, an } \\
\text { answer to contemporary } \\
\text { societal challenges? } \\
\text { Locating the concept in } \\
\text { theory and practice }\end{array}$ & 64 & Taylor \& Francis \\
\hline
\end{tabular}

It is believed that cite score can influence the selection of journal by some authors while publishing their articles. However, this is not very encouraging and Cite score should not be considered as the only measure; authors should also consider the best journal that can deliver the work to the right audience contributing to the progress in the appropriate field (Khudzari et al., 2018). To guide our fellow researchers in finding the appropriate journal for publishing their work, top 20 journals are listed in table 5 (appendix). Similarly, the top 20 most productive institutions in Social Innovation research are listed in Table 6 (appendix).

\subsection{ANALYSIS OF AUTHORS}

Through Bibliometric analysis, we were able to identify the top 10 authors in the filed with most publications in the area of Social Innovation. Hence, Frances R. Westley (University of Waterloo), Frank Moulaert (KU Leuven) and Michele Lee Moore (Stockholms Universitet) are identified as the top 3 authors in the field with the highest number of publications. Though the rankings of the authors based on the citations differ from this one as Frank Moulaert is the author with 410 citations while Michele Lee Moore and Frances R. Westley have 337 and 274 citations respectively. However, the rest of the seven authors have total citations, even less than 50. Table 2 shows that with nine publications in the field of SI Frances R. Westley (Canada) is the most prolific author who is affiliated with the University of Waterloo. Similarly, three of the top ten authors are from Canada. The rest of them are 
from Belgium, Sweden, UK, Spain, US, and Austria. Table 2 summarises the top 10 authors in the field of SI.

Table 2. Top 10 authors in the field of "Social Innovation."

\begin{tabular}{|c|c|c|c|c|c|c|c|c|}
\hline Rank & Author & $\begin{array}{l}\text { Scopus } \\
\text { Author ID }\end{array}$ & $\begin{array}{l}\text { Year of } 1^{\text {st }} \\
\text { Publication }\end{array}$ & $\begin{array}{l}\text { Total } \\
\text { publication }\end{array}$ & $\begin{array}{l}h- \\
\text { index }\end{array}$ & $\begin{array}{l}\text { Total } \\
\text { citation }\end{array}$ & $\begin{array}{l}\text { Current } \\
\text { affiliation }\end{array}$ & Country \\
\hline 1 & $\begin{array}{l}\text { Frances R. } \\
\text { Westley }\end{array}$ & 6602120712 & 2010 & 9 & 27 & 274 & $\begin{array}{l}\text { University of } \\
\text { Waterloo }\end{array}$ & Canada \\
\hline 2 & Frank Moulaert & 6603885203 & 2005 & 8 & 24 & 410 & KU Leuven & Belgium \\
\hline 3 & $\begin{array}{l}\text { Michele Lee } \\
\text { Moore }\end{array}$ & 37119327700 & 2011 & 7 & 14 & 337 & $\begin{array}{l}\text { Stockholms } \\
\text { Universitet }\end{array}$ & Sweden \\
\hline 4 & Maria Nijnik & 6602280629 & 2018 & 6 & 15 & 29 & $\begin{array}{l}\text { The James } \\
\text { Hutton } \\
\text { Institute }\end{array}$ & $\begin{array}{l}\text { United } \\
\text { Kingdom }\end{array}$ \\
\hline 5 & Micheal L. Shier & 24734119200 & 2014 & 6 & 15 & 36 & $\begin{array}{l}\text { University of } \\
\text { Toronto }\end{array}$ & Canada \\
\hline 6 & $\begin{array}{l}\text { Javier Castro- } \\
\text { Spila }\end{array}$ & $\begin{array}{l}3976449670 \\
0\end{array}$ & 2016 & 5 & 3 & 19 & $\begin{array}{l}\text { Innovation } \\
\text { Momentum } \\
\text { Lab, Donostia- } \\
\text { San Sebastian }\end{array}$ & Spain \\
\hline 7 & Femida Handy & 8907718600 & 2014 & 5 & 23 & 36 & $\begin{array}{l}\text { University of } \\
\text { Pennsylvania } \\
\text { Université du }\end{array}$ & $\begin{array}{l}\text { United } \\
\text { State }\end{array}$ \\
\hline 8 & Denis Harrisson & 6602959977 & 2006 & 5 & 8 & 21 & $\begin{array}{l}\text { Québec en } \\
\text { Outaouais }\end{array}$ & Canada \\
\hline 9 & Alice Ludvig & $\begin{array}{l}2407097150 \\
0\end{array}$ & 2018 & 5 & 9 & 19 & $\begin{array}{l}\text { Universitat } \\
\text { fur } \\
\text { Bodenkultur } \\
\text { Wien }\end{array}$ & Austria \\
\hline 10 & David R. Miller & $\begin{array}{l}5721086487 \\
8\end{array}$ & 2018 & 5 & 17 & 21 & $\begin{array}{l}\text { The James } \\
\text { Hutton } \\
\text { Institute }\end{array}$ & $\begin{array}{l}\text { United } \\
\text { Kingdom }\end{array}$ \\
\hline
\end{tabular}

\subsection{ANALYSIS OF COUNTRIES, INSTITUTIONS AND INTERNATIONAL COLLABORATION}

Taking into account the geographical distribution of scientific articles, Fig. 3 indicates that Canada (75.8\%), Italy (74.3\%) and Spain (74.3\%) are the countries among top 10 that have produced around $2 / 3$ of the single country publication (SCP). This suggests that Canada, Italy and Spain have a robust intra-country collaboration. On the contrary, the Netherlands is the country with the least percentage of single country publications with $47.8 \%$, where 36 out of 69 papers were linked to multiple affiliations from 26 different countries. Through international collaborations, not only do we extend the network, share knowledge and expertise, but it also serves as a means for ranking up. For instance, Brazil is a small country having 58.3\% SCP in which 21 out of 36 documents were collaborated internationally by 16 different counties. In addition to Fig. 4, we have also identified the top 50 productive Institutions that published research articles on Social Innovation. The details can be found in table S3 (appendix).

Table 3 shows that the concept of Social Innovation is widely known in the leading institutions of the world such as the University of Oxford, which is one of the top universities 
in the world. Universities that have contributed most by the largest number of publications are University of Waterloo (22), Politecnico di Milano (21), Universidad del Pais Vasco(16), University of Oxford (14) and TU Dortmund University(11). Table 3 also shows that the top 3 countries (Uk, USA, Italy) alone contribute $37.3 \%$ of the total social innovation literature publications. The top two countries that have contributed the most in Social Innovation research are UK and US, but that doesn't mean that the top authors in the field also belong to the same countries. Fig. 4 shows the top ten productive countries in social innovation publications.

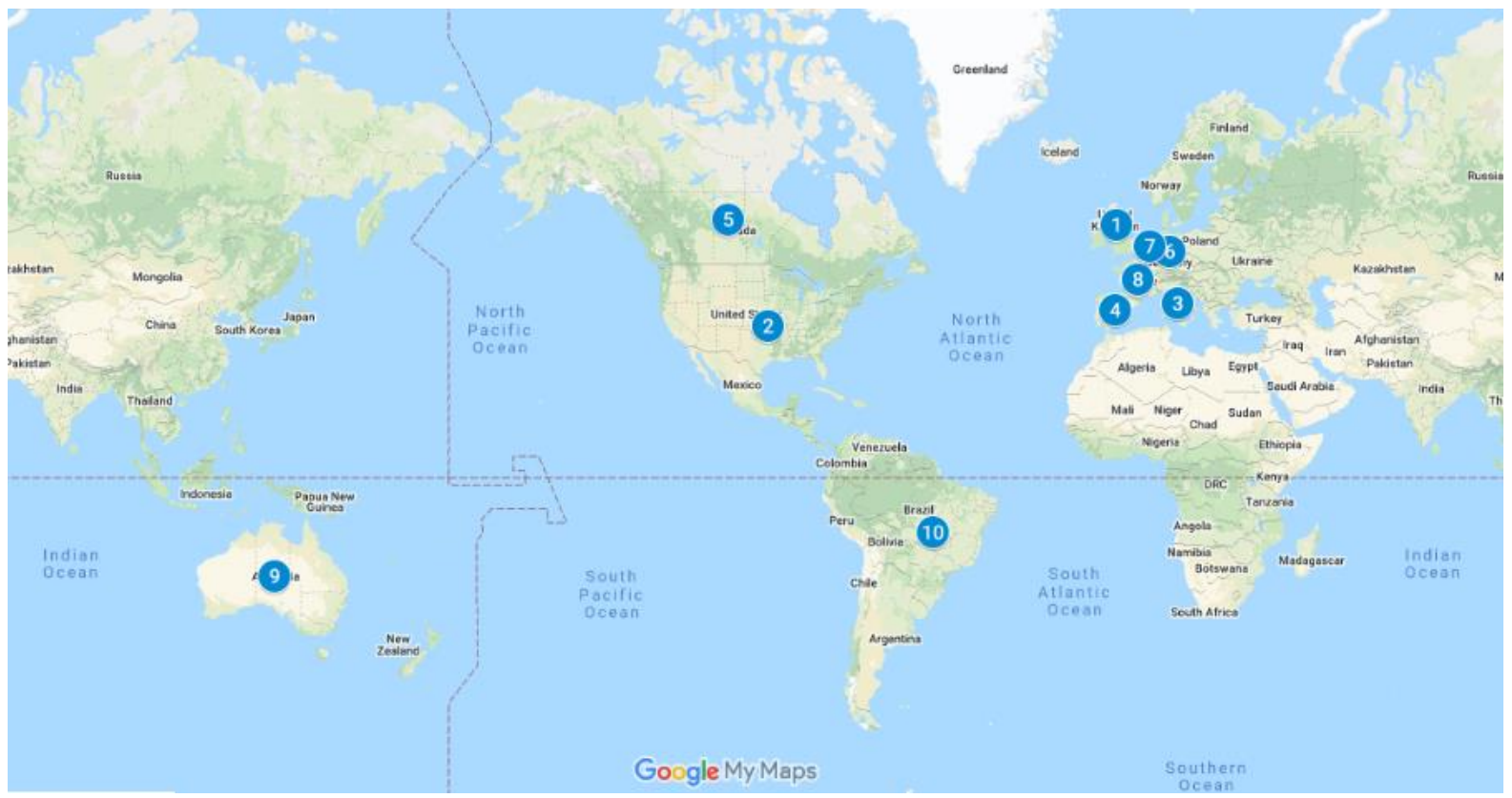

Fig. 4. Top 10 most productive counties and academic institutions in "Social Innovation" publications. TPC Total Publications of a country, TPi: Total Publications of a given educational institution, SPC: Single country publication

Table 3. Top 10 most productive counties and academic institutions in "Social Innovation" publications. (TPC Total Publications of a country, TPi: Total Publications of a given academic institution, SPC: Single country publication)

\begin{tabular}{llllll}
\hline Rank & Country & $\begin{array}{l}\text { Total Publications } \\
\text { (and \% contribution) }\end{array}$ & $\begin{array}{l}\text { Single Country } \\
\text { Publication (\%) }\end{array}$ & $\begin{array}{l}\text { The Most Productive Academic } \\
\text { Institution }\end{array}$ & TPi \\
1 & United Kingdom & $177(13.82 \%)$ & $50.3 \%$ & University of Oxford & 14 \\
2 & United States & $161(12.5 \%)$ & $65.8 \%$ & Boston College & 8 \\
3 & Italy & $141(11 \%)$ & $72.3 \%$ & Politecnico di Milano & 21 \\
4 & Spain & $113(8.82 \%)$ & $74.3 \%$ & Universidad del Pais Vasco & 16 \\
5 & Canada & $91(7.1 \%)$ & $75.8 \%$ & University of Waterloo & 22 \\
6 & Germany & $83(6.4 \%)$ & $66.3 \%$ & TU Dortmund University & 11 \\
7 & Netherlands & $69(5.3 \%)$ & $47.8 \%$ & Delft University of Technology & 10 \\
8 & France & $63(4.9 \%)$ & $60.3 \%$ & Universite Grenoble Alpes & 6 \\
9 & Australia & $52(4.1 \%)$ & $57.7 \%$ & University of Technology Sydney & 7 \\
10 & Brazil & $36(2.8 \%)$ & $58.3 \%$ & Universidade de Sao Paulo- USP 4 \\
\hline
\end{tabular}

The top two countries that have contributed most in the field of Social Innovation are the United Kingdom and the United States. Rest of the eight countries are from Europe, 
indicating that out of the total 85 countries data, only a few European countries managed to produce research on the area of Social Innovation. Total 53 countries out of 85 were able to contribute to the field with less than ten publications out of which 21 were those with just one publication each.

\subsection{CO-AUTHORSHIP ANALYSIS}

Fig. 5 shows the collaboration and co-authorship by countries in the social innovation field. The minimum number of documents from one country is set to 1, meaning we have included all the countries with at least one published document in the SI field. From the figure, two near located countries means that they have a strong affiliation with each other. A thick line connecting two countries also demonstrate the same. The countries are divided by their respective continents/regions, forming 5 clusters overall. The number of countries in per regions are as follows, Europe (34 countries), America (13 countries), Asia (21 countries), Africa (14 countries) and Oceania (2 countries). Therefore Europe is on top with the maximum number of countries that contributed to the social innovation research.

By doing co-authorship analysis with VoS viewer's help, we found that the United Kingdom (UK) has the largest affiliations with other countries regarding the publications in social innovation research. The UK has affiliations with 38 countries with 177 co-authorships. The USA is ranked second with 34 total affiliations with other countries and 163 co-authorships. Similarly, Italy is ranked third with 25 affiliations and has produced 141 research articles in the social innovation field. Spain and Canada are also listed in the top five countries with affiliations 18 and 15 with 91 and 83 co-authorships respectively.

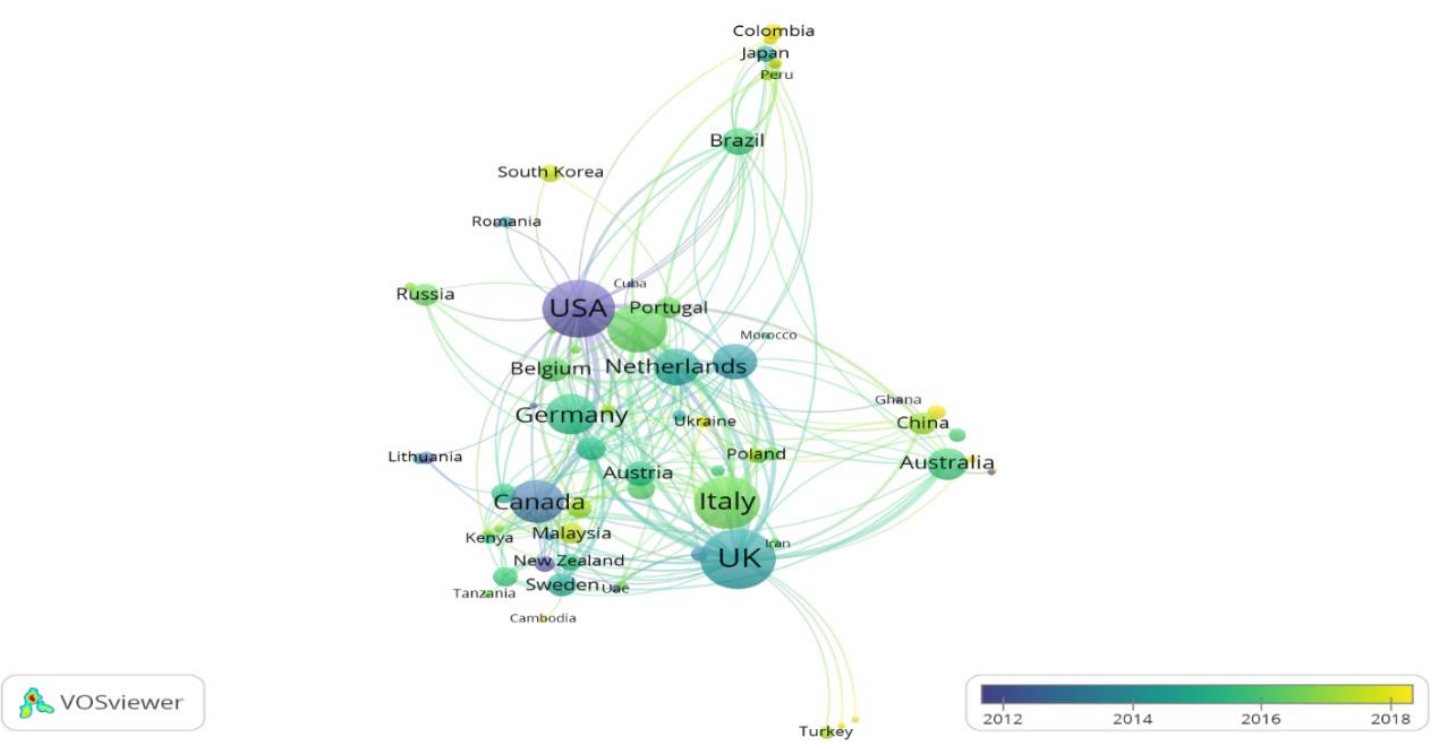

Fig. 5. Snapshot of the bibliometric map representing co-authorships in overlay visualisation mode.

Scientific collaboration is assumed to be a necessary element in enhancing the quality and impact of scientific research (Ozbag et al., 2019). There are many ways to increase international collaboration, for instance, increasing the number of visiting researchers, a 
variety of partnerships, and colossal funding dedicated to research. There is a need for a stable and flexible policy on research to boost international linkages (Khudzari et al., 2018).

\subsection{MAPPING OF RESEARCH THEMES IN THE SOCIAL INNOVATION}

In keyword analysis, we found that almost $17 \%$ of authors didn't mention the author keywords. We carried out an analysis of the author keywords using VoS viewer to observe which concepts are investigated with social innovation. The minimum number of occurrences of keywords was set to 5 while uploading the Scopus data on VOS viewer (van Eck \& Waltman, 2017), which resulted in the identification of 118 keywords from 3454 keywords. In other words, only 118 keywords met the threshold level of 5 occurrences per keyword. These 118 keywords had 616 links with each other forming a total link strength of 1179. In the next step, we re-labelled the identical and similar keywords excluding the country names and any irrelevant data and constructed a map of the resulting 97 author keywords in VoS viewer. The number of occurrences of a single keyword was set to 5 same as previously done. The succeeding 97 keywords have 495 links with each other making a total link strength of 1050.

We have identified the number of occurrences of some keyword related to social innovation research such as innovation $(n=79)$, social entrepreneurship $(n=76)$, social enterprise ( $n=49)$, sustainability ( $n=32), \operatorname{CSR}(n=22)$, governance $(n=21)$, social networks (21), entrepreneurship ( $n=20)$, social economy $(n=20)$, making them the widely used keywords in SI research. Findings suggest that innovations and social entrepreneurship are the most used keyword with social innovation. Our findings support the results of Silveira \& Zilber, (2017) that Social entrepreneurship and innovation are the most widely used keywords with social innovation research. Innovation has 79 occurrences, 52 links with other keywords and total link strength of 96 . At the same time, Social entrepreneurship has 76 occurrences, 36 links and 119 total link strength. This focus is more sociological than that of the traditional literature on innovation, given that terms such as 'capability approach', 'organisational learning', 'technological innovation, 'open innovation', 'sustainable innovation' are seen at the edge of the figure and have weaker ties (Silveira \& Zilber, 2017).

Fig. 6 shows that the overlay visualisation mode of VoS viewer results for author keyword analysis. The years on the bar shows the average publication year of the keywords. For instance, the yellow colour represents the publication year 2017, while the green one shows the average publication year 2016. Similarly, purple colour represents year average publication year 2014. The colour scheme also represents the variable with few occurrences. For instance, social value $(n=6)$, social justice $(n=5)$, citizen participation $(n=5)$, capability approach $(n=5)$, community development $(n=5)$ have been marked with yellow colour and are placed at the far edge. The overlay visualisation mode also recognises variables according to their average publication years which has fewer occurrences with social innovation research. Through this analysis, we can infer that there exist areas, for example, capability approach $(n=5)$, technological innovation $(n=5)$, value co-creation $(n=5)$, social value $(n=6)$, communication $(n=5)$, organisational learning $(n=5)$ etc. where more research is required to gain more understanding of the concept and extend the social innovation 
literature. It may also be noted that we have an English small alphabet " $n$ " which refers to the number of occurrences.

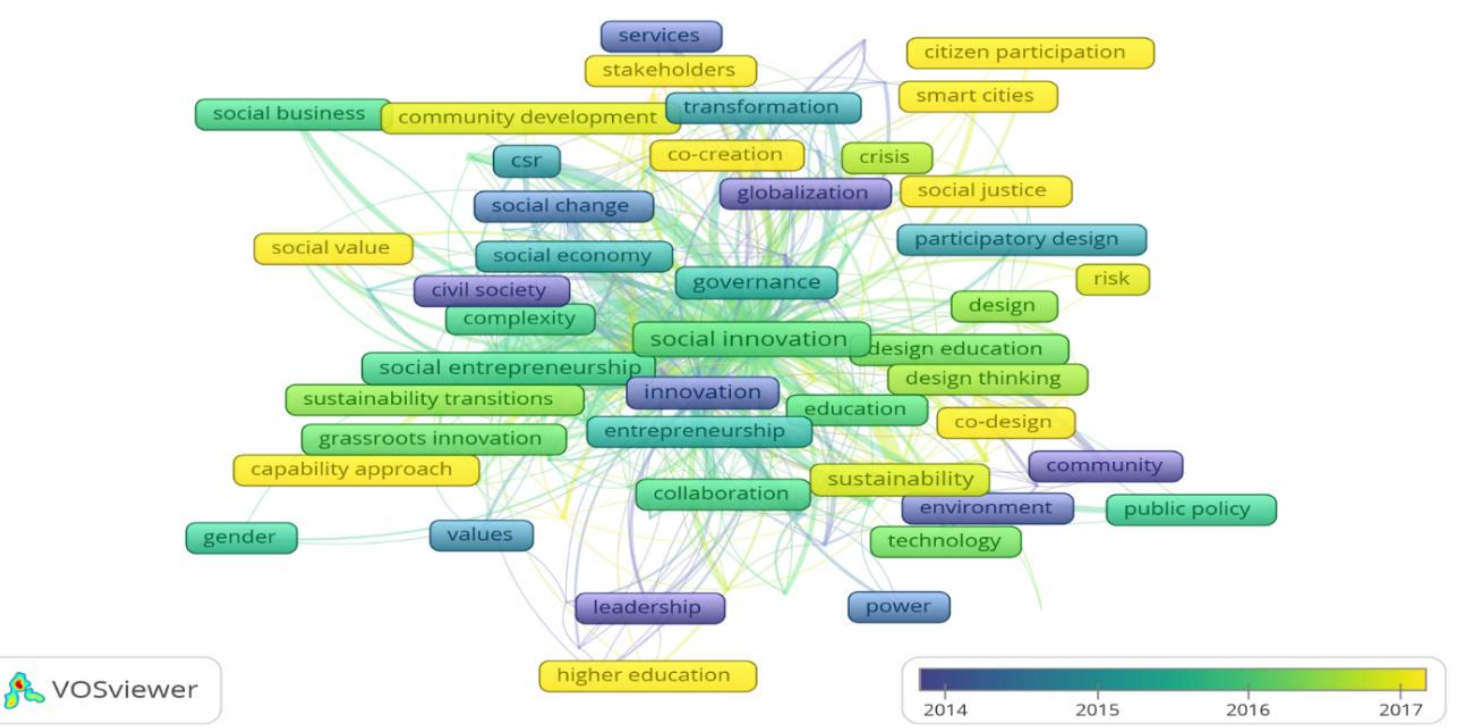

Fig. 6. Snapshot of the bibliometric map representing author keywords co-occurrences $(n=5)$ in overlay visualisation mode. Figure 6 is created in VoS viewer

\section{DISCUSSION AND CONCLUSION}

This study briefs the bibliometric analysis of SI literature published in the last 54 years, i.e. 1966-2019. Strong growth of articles in SI has been discovered from the year 2005. The European scholars make nearly $41 \%$ of the contribution in Si literature. The field of social innovation is multidisciplinary, and Sustainability is an eminent domain of SI research that has published most of the articles in the given area. The results of this study are in agreement with the previous studies (Ozbag et al., 2019) in terms of top most productive counties being the UK, USA and Italy. Correspondingly, University of Waterloo, Politecnico di Milano, Universidad del Pais Vasco are the top institutions that contributed to the SI field. Since 2016, there is a significant growth in the SI related research all over the world, indicating that social innovations have gained relevance among the academicians in recent years and this trend will continue to grow in the upcoming years. Consequently, there is an opportunity for researchers to conduct quantitative analysis given that the articles examined in this study were mostly qualitative in nature.

Interestingly, the findings of the study revealed a difference between top productive countries in terms of publications and single country publications by the topmost institute of that country. For instance, UK (177 publications) is crowned being the top productive country in the field, but Canada has contributed more than $2 / 3$ of the overall publications in the field (see table 2). Similarly, the results of this study demonstrate a clear difference between the numbers of publication made by an author against the highly cited authors. For example, Frank Moulaert is ranked second according to the number of publications but has the highest number of citations (see table 2). 
One of the few reasons behind the poor theory development in the social innovation field is the absence of a dedicated journal for SI research (Weerakoon et al., 2016). Therefore the publications in social innovation are distributed in different journals from various disciplines like social sciences, business management, environmental studies, economics, arts, engineering and medicine. This leads to a highly scattered and fragmented work with a lack of conceptual clarity and vague theoretical concepts provided by many authors from different fields. Scholars who chose to study social innovation should bear the responsibility to define, refine and further extend the construct (Weerakoon et al., 2016).

\section{LIMITATIONS}

The limitations of the study are the analysis of the study that has considered only one database, i.e. Scopus and limiting the study to just articles in the social innovation field. Another limitation is that it had taken a broader set of data from the time when the concept of social innovation was first introduced in 1966. Future studies could make an in-depth analysis by using a three to five years frame.

\section{Reference:}

Agostini, M. R., Vieira, L. M., Tondolo, R. P., Vilmar Antonio Gonçalves Tondolo, V. A. G. (2017). an Overview on Social Innovation Research: Brazilian Business Review, 14(4), 1-13. http://dx.doi.org/10.15728/bbr.2017.14.4.2

Baas, J., Schotten, M., Plume, A., Côté, G., \& Karimi, R. (2020). Scopus as a curated, highquality bibliometric data source for academic research in quantitative science studies. Quantitative Science Studies. https://doi.org/10.1162/qss_a_00019

Blanco-Ariza, A. B., Messino-Soza, A., Vázquez-García, Á. W., \& Melamed-Varela, E. (2019). Social innovation in the non-profit organization framework: A review. Social Sciences. https://doi.org/10.3390/socsci8080236

Caroli, M. G., Fracassi, E., Maiolini, R., \& Carnini Pulino, S. (2018). Exploring Social Innovation Components and Attributes: A Taxonomy Proposal. Journal of Social Entrepreneurship. https://doi.org/10.1080/19420676.2018.1448296

Foroudi, P., Akarsu, T. N., Marvi, R., \& Balakrishnan, J. (2020). Intellectual evolution of social innovation: A bibliometric analysis and avenues for future research trends. Industrial Marketing Management, March, 0-7. https://doi.org/10.1016/j.indmarman.2020.03.026

Fraisse, L. (2013). The social and solidarity-based economy as a new field of public action: a policy and method for promoting social innovation. The International Handbook on Social Innovation, 361-370. https://books.google.com.pk/books?hl=en\&lr=\&id=nDxOxm4Oy4cC\&oi=fnd\&pg= PA361\&dq=Fraisse $+(2013)+$ social+innovation\&ots=51ipoNZGWB\&sig=JDTTug $x Z O B$ RAQlqOGzY7tObF_GY

Gabor, D. (1970). Innovations: scientific, technological, and social. https://eric.ed.gov/?id=ED070258 
Gaitán-Angulo, M., Cubillos Díaz, J., Viloria, A., Lis-Gutiérrez, J. P., \& Rodríguez-Garnica, P. A. (2018). Bibliometric analysis of social innovation and complexity (databases scopus and dialnet 2007-2017). In Lecture Notes in Computer Science (including subseries Lecture Notes in Artificial Intelligence and Lecture Notes in Bioinformatics): Vol. 10943 LNCS. Springer International Publishing. https://doi.org/10.1007/978-3-319-93803-5_3

Jessop, B., Moulaert, F., Hulgård, L., \& Hamdouch, A. (2013). Social innovation research: a new stage in innovation analysis? In The International Handbook on Social Innovation. https://doi.org/10.4337/9781849809986.00020

Khudzari, J. M., Kurian, J., Tartakovsky, B., \& Raghavan, G. S. V. (2018). Bibliometric analysis of global research trends on microbial fuel cells using Scopus database. Biochemical Engineering Journal. https://doi.org/10.1016/j.bej.2018.05.002

Mirvis, P., Herrera, M. E. B., Googins, B., \& Albareda, L. (2016). Corporate social innovation: How firms learn to innovate for the greater good. Journal of Business Research. https://doi.org/10.1016/j.jbusres.2016.04.073

Moulaert, F., MacCallum, D., Mehmood, A., Hamdouch, A., Jessop, B., Moulaert, F., Hulgård, L., \& Hamdouch, A. (2013). Social innovation research: a new stage in innovation analysis? In The International Handbook on Social Innovation. https://doi.org/10.4337/9781849809993.00020

Mulgan, G. (2006). The Process of Social Innovation. Innovations: Technology, Governance, Globalisation. https://doi.org/10.1162/itgg.2006.1.2.145

Murray, R., Caulier-Grice, J., \& Mulgan, G. (2012). THE OPEN BOOK OF SOCIAL INNOVATION (2010). Revista Española Del Tercer Sector.

Ozbag, G. K., Esen, M., \& Esen, D. (2019). Bibliometric Analysis of Studies on Social Innovation. International Journal of Contemporary Economics and Administrative Sciences, 9(1), 25-45. https://doi.org/10.5281/zenodo.3262221

Pacheco, A. S. V., Santos, M. J., \& Da Silva, K. V. (2018). Social innovation: What do we know and do not know about it. International Journal of Innovation and Learning, 24(3), 301-326. https://doi.org/10.1504/IJIL.2018.094711

Silveira, F. F., \& Zilber, S. N. (2017). Is social innovation about innovation? A bibliometric study identifying the main authors, citations and co-citations over 20 years. International Journal of Entrepreneurship and Innovation Management, 27(6), 459-484. https://doi.org/10.1504/ijeim.2017.086936

Taylor, J. B. (1970). Introducing Social Innovation. The Journal of Applied Behavioral Science. https://doi.org/10.1177/002188637000600104

van der Have, R. P., \& Rubalcaba, L. (2016). Social innovation research: An emerging area of innovation studies? Research Policy, 45(9), 1923-1935. https://doi.org/10.1016/j.respol.2016.06.010 
van Eck, N. J., \& Waltman, L. (2014). Visualising Bibliometric Networks. In Measuring Scholarly Impact. https://doi.org/10.1007/978-3-319-10377-8_13

van Eck, N. J., \& Waltman, L. (2017). Citation-based clustering of publications using CitNetExplorer and Vosviewer. Scientometrics, 171(2), 1053-1070. https://doi.org/10.1007/s11192-017-2300-7

Weerakoon, C., McMurray, A., Rametse, N., \& Douglas, H. (2016). Social Innovation: a Preliminary Bibliometric Analysis. Social Innovation and Entrepreneurship Research Conference, Auckland 10-12 February 2016, February, 19.

Westley, F., McGowan, K., \& Tjörnbo, O. (2018). The Evolution of Social Innovation. The Evolution of Social Innovation, 2(1), 1-17. https://doi.org/10.4337/9781786431158

Wijk, J. van, Zietsma, C., Dorado, S., de Bakker, F. G. A., \& Martí, I. (2019). Social Innovation: Integrating Micro, Meso, and Macro Level Insights From Institutional Theory. Business and Society. https://doi.org/10.1177/0007650318789104

\section{APPENDIX}

Table 4. Search Strategy queries and string used in Scopus to identify articles for the final study

\begin{tabular}{|c|c|c|}
\hline Steps and queries & String & Results (doc) \\
\hline $\begin{array}{l}\text { Step } 1 . \\
\text { Article Main Search }\end{array}$ & TITLE-ABS ("Social Innovation") & $\begin{array}{l}3140 \\
\text { documents }\end{array}$ \\
\hline $\begin{array}{l}\text { Step } 2 . \\
\text { Limiting articles to } \\
\text { 'journal articles' and } \\
\text { publication year } 2019\end{array}$ & $\begin{array}{l}\text { TITLE-ABS ("social innovation") AND (LIMIT-TO (SRCTYPE, "j")) AND (LIMIT- } \\
\text { TO (DOCTYPE, "ar")) AND (EXCLUDE (PUBYEAR, 2O20) OR EXCLUDE } \\
\text { (PUBYEAR, 2021)) }\end{array}$ & $\begin{array}{l}1443 \\
\text { documents }\end{array}$ \\
\hline $\begin{array}{l}\text { Step } 3 . \\
\text { Removal of Review } \\
\text { articles from the } \\
\text { main search }\end{array}$ & $\begin{array}{l}\text { TITLE-ABS ("Social Innovation") AND (TITLE ("recent" OR progress OR } \\
\text { review OR critical OR revisit OR advance OR development OR highlight } \\
\text { OR perspective OR prospect OR trends OR bibliometric OR } \\
\text { scientometric) OR (ABS (progress OR review OR bibliometric OR } \\
\text { scientometric ))) AND (LIMIT-TO (SRCTYPE, "j")) AND (LIMIT-TO (DOCTYPE, } \\
\text { "ar")) AND (EXCLUDE (PUBYEAR, 2O2O) OR EXCLUDE (PUBYEAR, 2O21)) }\end{array}$ & $\begin{array}{l}300 \\
\text { documents }\end{array}$ \\
\hline $\begin{array}{l}\text { Step } 4 . \\
\text { Final database (after } \\
\text { removing all review } \\
\text { and meta-analysis } \\
\text { articles) }\end{array}$ & $\begin{array}{l}\text { TITLE-ABS ("social innovation") AND NOT EID ( } 2-s 2.0-85078422106 \text { OR 2- } \\
\text { s2.0-85068611837 OR 2-s2.0-85090885681 OR 2-s2.0-85074593276 OR 2- } \\
\text { s2.0-85053259504 OR 2-s2.0-85070521459 OR 2-s2.0-85073517424 OR 2- } \\
\text { s2.0-85072514899 OR 2-s2.0-85073335222 OR 2-s2.0-85067835411 OR 2- } \\
\text { s2.0-85071198469 OR 2-s2.0-85058617599 OR 2-s2.0-85066013492 OR 2- } \\
\text { s2.0-85084253827 OR 2-s2.0-85039924332 OR 2-s2.0-85067230737 OR 2- } \\
\text { s2.0-85062366401 OR 2-s2.0-85077363710 OR 2-s2.0-85064433468 OR 2- } \\
\text { s2.0-85071381457 OR 2-s2.0-85077684469 OR 2-s2.0-85073642293 OR 2- } \\
\text { s2.0-85077675526 OR 2-s2.O-85047262633 OR 2-s2.0-85057043756 OR 2- } \\
\text { s2.0-85056706811 OR 2-s2.0-85054224886 OR 2-s2.0-85045265214 OR 2- }\end{array}$ & $\begin{array}{l}1281 \\
\text { documents }\end{array}$ \\
\hline
\end{tabular}


s2.0-85056619088 OR 2-s2.0-85063219616 OR 2-s2.0-85054929366 OR 2s2.0-85047794591 OR 2-s2.0-85058341724 OR 2-s2.0-85045728951 OR 2s2.0-85048101304 OR 2-s2.0-85018369159 OR 2-s2.0-85045295641 OR 2s2.0-85029927371 OR 2-s2.0-85058547570 OR 2-s2.0-85044711967 OR 2s2.0-85071146435 OR 2-s2.0-85062705079 OR 2-s2.0-85062723228 OR 2s2.0-85051348565 OR 2-s2.0-85019659445 OR 2-s2.0-85034220143 OR 2s2.0-85032823444 OR 2-s2.0-85027407301 OR 2-s2.0-85067688084 OR 2s2.0-85020918064 OR 2-s2.0-85018320890 OR 2-s2.0-85016503812 OR 2s2.0-85021379569 OR 2-s2.0-85008674661 OR 2-s2.0-85008676999 OR 2s2.0-85010645189 OR 2-s2.0-85019541365 OR 2-s2.0-84977177772 OR 2s2.0-85013278399 OR 2-s2.0-85030976529 OR 2-s2.0-85046485892 OR 2s2.0-85046031045 OR 2-s2.0-85044816744 OR 2-s2.0-85022337600 OR 2s2.0-85028608779 OR 2-s2.0-85029954618 OR 2-s2.0-85021865616 OR 2s2.0-85029746633 OR 2-s2.0-85035363786 OR 2-s2.0-85059815949 OR 2s2.0-84992645474 OR 2-s2.0-84978924542 OR 2-s2.0-84960331447 OR 2s2.0-84966708307 OR 2-s2.0-84975701658 OR 2-s2.0-84979257519 OR 2s2.0-84969179665 OR 2-s2.0-84978518033 OR 2-s2.0-84994515749 OR 2s2.0-85073070248 OR 2-s2.0-85073076537 OR 2-s2.0-85011580193 OR 2s2.0-85013989538 OR 2-s2.0-85008925729 OR 2-s2.0-85011585959 OR 2s2.0-85026781369 OR 2-s2.0-84975221817 OR 2-s2.0-84940797562 OR 2s2.0-84930919934 OR 2-s2.0-85028233610 OR 2-s2.0-84951105253 OR 2s2.0-84943570734 OR 2-s2.0-84935147540 OR 2-s2.0-84949222995 OR 2s2.0-84937830762 OR 2-s2.0-84929275580 OR 2-s2.0-84946721044 OR 2s2.0-84943516171 OR 2-s2.0-85028546190 OR 2-s2.0-85041649692 OR 2s2.0-84938599515 OR 2-s2.0-85000444090 OR 2-s2.0-84961381982 OR 2s2.0-84988635535 OR 2-s2.0-85048715847 OR 2-s2.0-84921309434 OR 2s2.0-84907274813 OR 2-s2.0-84904209867 OR 2-s2.0-84901932451 OR 2s2.0-84919766372 OR 2-s2.0-84910054335 OR 2-s2.0-84917708947 OR 2s2.0-85072896769 OR 2-s2.0-85029780889 OR 2-s2.0-84897078664 OR 2s2.0-84908017017 OR 2-s2.0-84937922809 OR 2-s2.0-84899919508 OR 2s2.0-84909948541 OR 2-s2.0-84892720414 OR 2-s2.0-84879966638 OR 2s2.0-84881111318 OR 2-s2.0-84885028275 OR 2-s2.0-84896518359 OR 2s2.0-84879420033 OR 2-s2.0-84893365963 OR 2-s2.0-84878382645 OR 2s2.0-84870294879 OR 2-s2.0-84855352580 OR 2-s2.0-84876424091 OR 2s2.0-84856677381 OR 2-s2.0-84856446491 OR 2-s2.0-79960874580 OR 2s2.0-80052235324 OR 2-s2.0-79952195989 OR 2-s2.0-72749121997 OR 2s2.0-70349633188 OR 2-s2.0-70350536843 OR 2-s2.0-34547586026 OR 2s2.0-34250682649 OR 2-s2.0-37849187293 OR 2-s2.0-33749080100 OR 2s2.0-0346335438 OR 2-s2.0-67650599221 OR 2-s2.0-34247451237 OR 2s2.0-0002433505 OR 2-s2.0-79959632557 OR 2-s2.0-0012280660 OR 2s2.0-77950676351 OR 2-s2.0-0010859346 OR 2-s2.0-44949275992 OR 2s2.0-84963086991 OR 2-s2.0-0025589215 OR 2-s2.0-45149138426 OR 2s2.0-0024151854 OR 2-s2.0-0023345945 OR 2-s2.0-0022723899 OR 2-s2.O84982731550 OR 2-s2.0-0018409871 OR 2-s2.0-0018203852 OR 2-s2.OO016186788 OR 2-s2.0-33947309605) AND (LIMIT-TO (SRCTYPE, "j")) AND (LIMIT-TO (DOCTYPE, "ar")) AND (EXCLUDE (PUBYEAR, 2020) OR EXCLUDE (PUBYEAR, 2O21))

Table 5. The top cite score journals publishing Social Innovation research with minimum 8 research articles

\begin{tabular}{llllc}
\hline Rank & Journal Name & $\begin{array}{l}\text { No. of } \\
\text { Publications }\end{array}$ & Publisher & $\begin{array}{l}\text { Cite Score } \\
\mathbf{2 0 1 9}\end{array}$ \\
\hline 1 & Sustainability Switzerland & 42 & $\begin{array}{l}\text { Multidisciplinary } \\
\text { Publishing Institute (MDPI) }\end{array}$ & Digital \\
\hline
\end{tabular}




\begin{tabular}{|c|c|c|c|c|}
\hline 2 & Design Journal & 31 & Taylor \& Francis & 0.6 \\
\hline 3 & Journal of Social Entrepreneurship & 23 & Taylor \& Francis & 2.6 \\
\hline 4 & Ecology and Society & 16 & The Resilience Alliance & 7.5 \\
\hline 5 & Innovation & 13 & Taylor \& Francis & 2.9 \\
\hline 6 & $\begin{array}{l}\text { Ciriec Espana Revista De Economia } \\
\text { Publica Social Y Cooperativa }\end{array}$ & 12 & CIRIEC-ESPANA & 1.2 \\
\hline 7 & Futures & 12 & Elsevier & 3.9 \\
\hline 8 & Salute E Societa & 12 & Franco Angeli Edizioni & 0.1 \\
\hline 9 & $\begin{array}{l}\text { Technological Forecasting and Social } \\
\text { Change }\end{array}$ & 12 & Elsevier & 8.7 \\
\hline 10 & Voluntas & 12 & Springer Nature & 2.9 \\
\hline 11 & $\begin{array}{l}\text { Emerald Emerging Markets Case } \\
\text { Studies }\end{array}$ & 11 & Emerald & 0.1 \\
\hline 12 & Forest Policy and Economics & 11 & Elsevier & 5.7 \\
\hline 13 & Journal of Cleaner Production & 10 & Elsevier & 10.9 \\
\hline 14 & Design and Culture & 9 & Taylor \& Francis & 0.6 \\
\hline 15 & Espacios & 9 & $\begin{array}{l}\text { Sociacion de Profesionales y } \\
\text { Tecnicos del CONICIT }\end{array}$ & 0.5 \\
\hline 16 & Journal of Business Research & 9 & Elsevier & 8.9 \\
\hline 17 & $\begin{array}{l}\text { Annals of Public and Cooperative } \\
\text { Economics }\end{array}$ & 8 & Wiley-Blackwell & 2.3 \\
\hline 18 & European Urban and Regional Studies & 8 & SAGE & 7.3 \\
\hline 19 & $\begin{array}{l}\text { Journal of Human Development and } \\
\text { Capabilities }\end{array}$ & 8 & Taylor \& Francis & 2.4 \\
\hline 20 & Urban Studies & 8 & SAGE & 5.8 \\
\hline
\end{tabular}

Table 6. The top 20 most productive institutions in "Social Innovation" Research

\begin{tabular}{llll}
\hline Rank & Institution & Country & No. of Publications \\
\hline 1 & University of Waterloo & Canada & 22 \\
2 & Politecnico di Milano & Italy & 21 \\
3 & Université du Québec à Montréal & Canada & 17 \\
4 & Universidad del Pais Vasco & Spain & 16 \\
5 & University of Oxford & United Kingdom & 14 \\
6 & KU Leuven & Belgium & 12 \\
7 & TU Dortmund University & Germany & 11 \\
8 & Universitat de Barcelona & Spain & 10 \\
9 & University of Valencia & Spain & 10 \\
10 & Newcastle University & United Kingdom & 10 \\
11 & Delft University of Technology & Netherlands & 10 \\
12 & Universitat Autònoma de Barcelona & Spain & 10 \\
13 & The University of Manchester & United Kingdom & 9 \\
14 & University of Leeds & United Kingdom & 9 \\
15 & Wageningen University \& Research & Netherlands & 8 \\
16 & Glasgow Caledonian University & United Kingdom & 8 \\
17 & Università degli Studi di Pavia & Italy & 8 \\
18 & Boston College & United States & 8 \\
19 & The James Hutton Institute & United Kingdom & 8 \\
20 & Sozialforschungsstelle Dortmund & Germany & 7 \\
\hline
\end{tabular}

